\title{
Parathyroid hormone promotes osteoblastic differentiation of endothelial cells via the extracellular signal-regulated protein kinase 1/2 and nuclear factor- $\kappa B$ signaling pathways
}

\author{
ZHI-YUAN CHENG ${ }^{1}$, TING YE ${ }^{1}$, QIU-YANG LING ${ }^{2}$, TING WU ${ }^{2}$, GANG-YONG WU ${ }^{2}$ and GANG-JUN ZONG ${ }^{1,2}$ \\ ${ }^{1}$ Department of Cardiology, Wuxi Clinical Hospital, Anhui Medical University; \\ ${ }^{2}$ Department of Cardiology, 101 Hospital of PLA, Wuxi, Jiangsu 214044, P.R. China
}

Received December 25, 2016; Accepted September 22, 2017

DOI: $10.3892 /$ etm.2017.5545

\begin{abstract}
Vascular calcification (VC) occurs in patients with chronic kidney disease (CKD) and contributes to cardiovascular dysfunction and mortality. Parathyroid hormone (PTH) is a crucial regulator of VC. High PTH serum levels constitute as a major risk factor for patients with CKD. However, the effect and mechanism of PTH on osteoblastic differentiation in endothelial cells have not been fully elucidated. In the present study, the role of PTH in VC was investigated using an in vitro calcification model. Endothelial cells were stimulated with PTH in the femto- to picomolar range. As determined by western blot analysis and ELISA, osteoblastic differentiation, as indicated by the BMP2 marker, occurred with maximum effect at $1 \times 10^{-10} \mathrm{mmol} / 1 \mathrm{PTH}$. The results indicate that PTH promotes osteoblastic differentiation of endothelial cells, as demonstrated by the increased expression of bone morphogenetic protein (BMP) 2 and BMP4. In addition, western blot analysis revealed that PTH activated the extracellular signal-regulated protein kinase (Erk)1/2 and nuclear factor (NF) $-\kappa B$ signaling pathways. However, reverse transcription-quantitative polymerase chain reaction demonstrated that inhibitors specific to Erk1/2 and $N F-\kappa B$ eradicated the effect of PTH treatment on BMP2, BMP4, ALP and RUNX2 expression. These results demonstrate that PTH promotes the osteoblastic differentiation of endothelial cells via the Erk1/2 and NF- $\kappa \mathrm{B}$ signaling pathways, which suggests a potential role of PTH in the promotion of VC. These findings provide an insight into the association between PTH and cardiovascular disease.
\end{abstract}

Correspondence to: Professor Gang-Jun Zong, Department of Cardiology, Wuxi Clinical Hospital, Anhui Medical University, 101 Xing Yuan Road, Wuxi, Jiangsu 214044, P.R. China E-mail: zonggj@163.com

Key words: parathyroid hormone, endothelial cells, vascular calcification, chronic kidney disease, extracellular signal-regulated protein kinase 1/2 signaling pathway, nuclear factor- $\kappa \mathrm{B}$ signaling pathway

\section{Introduction}

Vascular calcification (VC) is associated with cardiovascular-related mortality in patients with chronic kidney disease (CKD) (1). VC is considered to be a passive and degenerative process. However, previous findings have indicated that VC may be a pathobiological process with respect to embryonic bone formation. It has been demonstrated in animal models that VC may be induced by stimulating various genes, including bone morphogenetic protein (BMP)2, BMP4 (2,3), runt-related transcription factor (RUNX)2 and alkaline phosphatase (ALP) (4). Previous studies have revealed that BMP2 and BMP4, members of the transforming growth factor-b cytokine superfamily, participate in vascular calcification (5). Vascular endothelial and smooth muscle are key sources of BMPs, which when detected in calcified blood vessels may be associated with enhanced vascular calcification (6).

Parathyroid hormone (PTH) is a critical bridge between bone metabolism and cardiovascular disease (7). PTH regulates plasma calcium concentration and maintains skeletal integrity (8). PTH receptors are present throughout the cardiovascular system, including in smooth muscle cells, endothelial cells and cardiomyocytes (9-11). PTH participates in the development of $\mathrm{VC}$, which is elevated in patients with chronic renal failure (12). PTH may therefore serve a role in the pathophysiology of cardiovascular disease (13). A series of previous studies $(14,15)$ have suggested that PTH may directly induce endothelial dysfunction and contribute to $\mathrm{VC}$. However, the underlying mechanisms of this remain unclear.

In the present study, it was hypothesized that PTH may be associated with the regulation of osteoblastic differentiation in endothelial cells. To determine its effects and develop a model for the mechanism of action, PTH was used to induce calcification of endothelial cells in culture as previously described (16). The effect of PTH on the osteoblastic differentiation of endothelial cells and the associated cell signaling pathways, Erk1/2 and NF- $\kappa$ B, was also examined. Elucidating the role of PTH may provide critical information concerning bone disease as well as novel preventive and therapeutic opportunities for patients with cardiovascular disease. 


\section{Materials and methods}

Ethical statement. The present study was approved by the Animal Ethics Committee of Anhui Medical University (Wuxi, China).

Cell culture and treatment. Primary human umbilical vein endothelial cells (HUVECs) were purchased (cat. no. JL10025; Shanghai Jianglin Biotechnology Company, Shanghai, China) and cultured according to the manufacturer's recommended protocol. Cells were maintained at $37^{\circ} \mathrm{C}$ in a humidified atmosphere containing $5 \% \mathrm{CO}_{2}$ and were cultured in Dulbecco's modified Eagle's medium (DMEM) supplemented with $10 \%$ fetal bovine serum (Gibco; Thermo Fisher Scientific, Inc., Waltham, MA, USA). DMEM was replaced daily. When the cultures reached $80 \%$ confluence, adherent cells were detached using $0.05 \%$ trypsin and $0.03 \%$ EDTA in PBS for $2 \mathrm{~min}$ at $37^{\circ} \mathrm{C}$. The collected cells $\left(1 \times 10^{5}\right.$ cells/well $)$ were cultured in DMEM with $5 \% \mathrm{CO}_{2}$. The cells were washed once with PBS for $2 \mathrm{~min}$, resuspended in DMEM and aliquoted into 12-well plates at $37^{\circ} \mathrm{C}$ at a density of $1 \times 10^{6}$ cells/well. Confluent cultures of HUVECs were passaged 3-4 times and subsequently incubated with various concentrations $\left(10^{-11}, 10^{-10}\right.$, $10^{-9}$ and $10^{-8} \mathrm{mmol} / \mathrm{l}$ ) of a PTH peptide fragment (teriparatide; residues 1-34; R\&D Systems, Inc., Minneapolis, MN, USA) at $37^{\circ} \mathrm{C}$ for $72 \mathrm{~h}$. Western blot analysis and ELISA analysis were subsequently performed to detect BMP2 and BMP4. HUVECs without PTH treatment were used as a control.

Additionally, HUEVC's were incubated with $10^{-10} \mathrm{mmol} / \mathrm{l}$ PTH for increasing time periods (5-60 min) to investigate the effect of PTH on the Erk $1 / 2$ and $N F-\kappa B$ signaling pathways. The cells were seeded at $1 \times 10^{5}$ cells/well in 24 -well plates and cultured at $37^{\circ} \mathrm{C}$.

HUVECs were also incubated with Erk1/2 inhibitor, U0126 and $\mathrm{NF}-\kappa \mathrm{B}$ inhibitor, pyrrolidine dithiocarbamate (PDTC) (both Tocris Bioscience, Bristol, UK). There were three treatment groups and the HUEVCs were incubated with U0126 $(1 \mu \mathrm{M})$, PDTC $(10 \mu \mathrm{M})$ or U0126 $(1 \mu \mathrm{M})+$ PDTC $(10 \mu \mathrm{M})$ for $2 \mathrm{~h}$ prior to treatment with $10^{-10} \mathrm{mmol} / 1 \mathrm{PTH}$ for $72 \mathrm{~h}$. The cells were seeded at $1 \times 10^{5}$ cells/well and the inhibitors were added to the cells at $37^{\circ} \mathrm{C}$.

Western blot analysis. Western blot analysis was used to detect BMP2, BMP4, phosphorylated and total Erk1/2, and phosphorylated and total $\mathrm{NF}-\kappa \mathrm{B} . \beta$-actin was used as a loading control. Following PTH stimulation for 72 h, HUVECs were lysed with ice-cold radioimmunoprecipitation assay lysis buffer (Thermo Fisher Scientific, Inc.). Lysates were subjected to centrifugation at $12,000 \mathrm{x}$ g for $10 \mathrm{~min}$ at $4^{\circ} \mathrm{C}$. Protein concentration in the supernatant was measured using a BCA kit (Beijing Solarbio Science \& Technology Co., Ltd., Beijing, China). Total protein (20 $\mu \mathrm{g} /$ lane), which was extracted from the HUVECs was separated by $10-12 \%$ SDS-PAGE and transferred to a polyvinylidene difluoride membrane (EMD Millipore, Billerica, MA, USA), which was blocked with $5 \%$ bovine serum albumin (cat. no. ST023; Beyotime Institute of Biotechnology, Haimen, China) in PBS for $1 \mathrm{~h}$ at room temperature $\left(25^{\circ} \mathrm{C}\right)$. Blots were exposed to primary antibodies directed against BMP2 (1:1,000; cat. no. ab183729), BMP4 (1:2,000; cat. no. ab124715) (both Abcam, Cambridge, UK), Erk1/2 (1:1,000; cat. no. 4695),

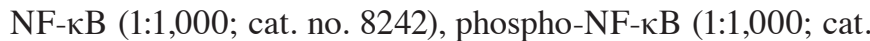
no. 3033), phosphor-Erk1/2 (1:1,000; cat. no. 4370), and $\beta$-actin (1:1,000, cat. no. 4970) (both CST Biological Reagents Co., Ltd., Shanghai, China) overnight at $4^{\circ} \mathrm{C}$. Following washing three times with tris-buffered saline with Tween-20 for $10 \mathrm{~min}$ each time, the membranes were incubated with anti-rabbit immunoglobulin G, horseradish peroxidase-linked antibodies (1:3,000; cat. no. 7074; CST Biological Reagents Co., Ltd.,) for $1 \mathrm{~h}$ at room temperature. Thereafter, signals were detected using a chemiluminescence detection kit (Merck KGaA, Darmstadt, Germany). The relative protein expression levels were measured using the accompanying computerized image analysis program (ImageQuant LAS 4000 version 1.2; GE Healthcare Life Sciences, Little Chalfont, UK).

Reverse transcription-quantitative polymerase chain reaction (RT-qPCR). Total RNA from HUVECs was extracted using the TRIzol reagent (Invitrogen; Thermo Fisher Scientific, Inc.). RNA was reverse transcribed to cDNA using a PrimeScript RT Reagent Kit (Takara Biotechnology Co., Ltd., Dalian, China) according to the manufacturer's protocols. RT-qPCR

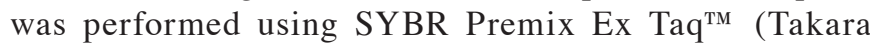
Biotechnology Co., Ltd.) according to the manufacturer's protocol, on a CFX96-Real-Time system. Sample preparations whose 260/280 nm absorbance ratio fell between 1.8 and 2.0 were selected as templates. Genecopoeia (Rockville, MD,USA) designed and synthesized the primers. The RT-qPCR primers were as follows: BMP2 forward, 5'-TCAAGCCAAACACAC AAACAGC-3' and reverse, 5'-ACGTCTGAACAATGGCAT GA-3'; RUNX2 forward, 5'-CCGGTCTCCTTCCAGGAT-3' and reverse, 5'-GGGAACTGCTGCTGTGGCTTC-3'; ALP forward, 5'-TGTTCCTGGGAGATGGTATG-3' and reverse, 5'-CCTGAGCGTTGGTGTTGTA-3'; BMP4 forward 5'-CAC CTCAACTCAACCAACCA-3' and reverse, 5'-CAACACCAC CTTGTCATACTCA-3'; GAPDH forward, 5'-GGCTGCCCA GAACATCAT-3' and reverse, 5'-CGGACACATTGGGGG TAG-3'. The PCR conditions included an initial denaturation for $5 \mathrm{sec}$ at $95^{\circ} \mathrm{C}$, followed by 40 cycles of denaturation for $10 \mathrm{sec}$ at $95^{\circ} \mathrm{C}$, annealing for $20 \mathrm{sec}$ at $60^{\circ} \mathrm{C}$ and extension for $15 \mathrm{sec}$ at $72^{\circ} \mathrm{C}$. All experiments were repeated in triplicate. The relative expression levels of mRNA were calculated with the $2^{-\Delta \Delta \mathrm{Cq}}$ method (17) and expression was normalized to that of GAPDH.

ELISA analysis. Levels of BMP2 [cat. no. EK11082-96T; Hangzhou MultiSciences (Lianke) Biotech, Co., Ltd., Hangzhou, China] and BMP4 (cat. no. DBP400; R\&D Systems, Inc., Minneapolis, MN, USA) in supernatants were analyzed using ELISA kits according to the manufacturer's protocol. Absorbance was read at $450 \mathrm{~nm}$ on a microplate reader (Bio-Rad Laboratories, Inc., Hercules, CA, USA). Results were determined within the linear range of the standard curve.

Statistical analysis. Data are presented as the mean \pm standard deviation. All statistical analyses were performed using GraphPad Prism software (version 5.0; GraphPad Software, Inc., La Jolla, CA, USA). Each treatment group was compared with the control group using the Dunnett's test or one-way analysis of variance with the post hoc Bonferroni or Dunn test to analyze differences between experimental groups. $\mathrm{P}<0.05$ 
A
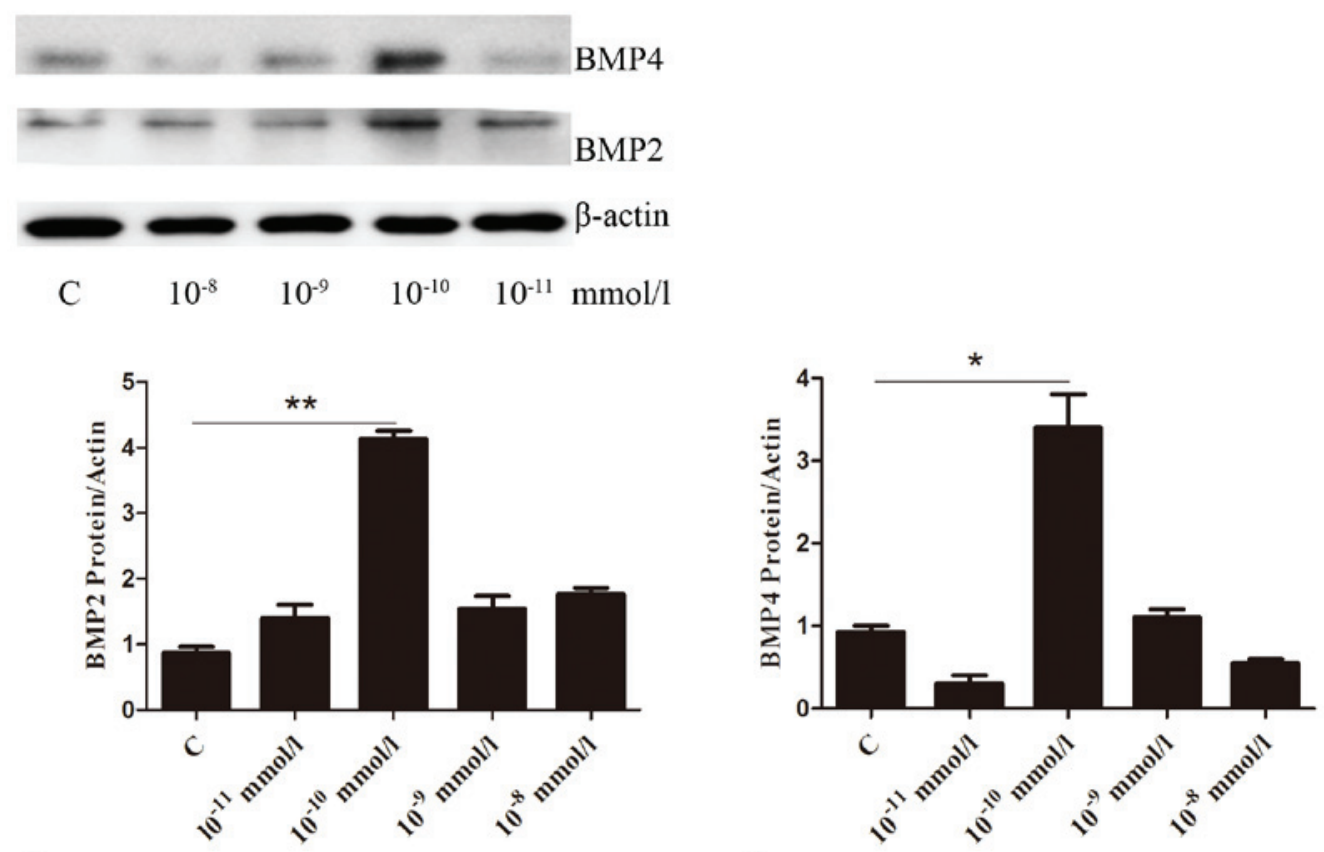

B
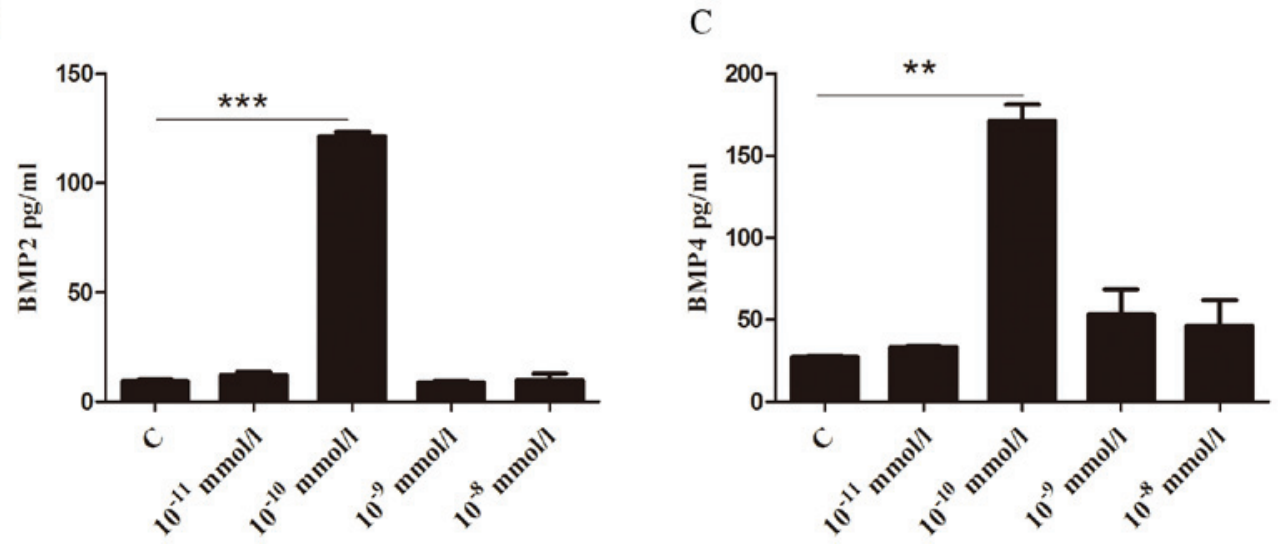

Figure 1. PTH upregulates the production of BMP2 and BMP4 in HUVECs. HUVECs were treated with $10^{-8}$ to $10^{-11} \mathrm{mmol} / 1$ of PTH for $72 \mathrm{~h}$. (A) Representative immunoblots of three separate experiments and normalized densitometry data indicated that $10^{-10} \mathrm{mmol} / 1$ of PTH resulted in the greatest expression levels compared with the control. However, concentrations greater than $10^{-10} \mathrm{mmol} / 1 \mathrm{PTH}$ had no additional effect compared with the control. $\beta$-actin was used as an internal control. (B) Determination of BMP2 concentration using ELISA from HUVECs treated with PTH. (C) Determination of BMP4 concentration by ELISA from HUVECs treated with PTH. BMP2 and BMP4 levels increased significantly compared with the control after $10^{-10} \mathrm{mmol} / 1 \mathrm{PTH}$ stimulation. $\mathrm{n}=3$. ${ }^{*} \mathrm{P}<0.05,{ }^{* *} \mathrm{P}<0.01$ and ${ }^{* * * *} \mathrm{P}<0.001$. PTH, parathyroid hormone; BMP, bone morphogenetic protein; HUVECs, human umbilical vein endothelial cells; $\mathrm{C}$, control cells with no PTH treatment.

was considered to indicate a statistically significant difference. All experiments were repeated at least three times.

\section{Results}

PTH promotes osteoblastic differentiation of HUVECs. Recent data has suggested that $\mathrm{VC}$ occurs as a result of osteoblastic differentiation of HUVECs, in which BMP2 and BMP4 are significantly upregulated (18). In the present study, the expression levels of BMP2 and BMP4 were used as markers to indicate osteoblastic differentiation of HUVECs as previously described (19). Results indicated that $10^{-10} \mathrm{mmol} / 1$ of PTH resulted in the greatest expression of BMP2 $(\mathrm{P}<0.01)$ and BMP4 $(\mathrm{P}<0.05)$ compared with the control (Fig. 1). However, concentrations $>10^{-10} \mathrm{mmol} / \mathrm{l}$ PTH had no significant effect compared with the control (Fig. 1). The results indicate that a maximal effect was achieved when the PTH concentration was $10^{-10} \mathrm{mmol} / \mathrm{l}$.
Furthermore, the increased expression of BMP2 and BMP4 following PTH stimulation suggests that PTH may promote osteoblastic differentiation.

PTH activates the Erk1/2 and NF- $\kappa B$ signaling pathways. The Erk1/2 and NF- $\kappa B$ signaling pathways serve a crucial role in controlling cell differentiation (20). Activation of these signaling pathways may serve as a marker for VC in HUVECs. The results demonstrate that treatment with $10^{-10} \mathrm{mmol} / 1 \mathrm{PTH}$ for $5 \mathrm{~min}$ promotes the phosphorylation of Erk1/2 compared with no treatment, with peak activation occurring at $45 \mathrm{~min}$ of exposure, how ever the levels of phospho-Erk1/2 were significantly decreased at 60 min compared with 45 min exposure. ( $\mathrm{P}<0.01$; Fig. $2 \mathrm{~A})$. Treatment with PTH also increases the phosphorylation of NF-kB following 5 min of exposure, with peak activation occurring at $45 \mathrm{~min}(\mathrm{P}<0.01)$, the levels of phospho-NF- $\mathrm{\kappa B}$ decreased at $60 \mathrm{~min}$, however the change was not significant (Fig. 2B). 
A

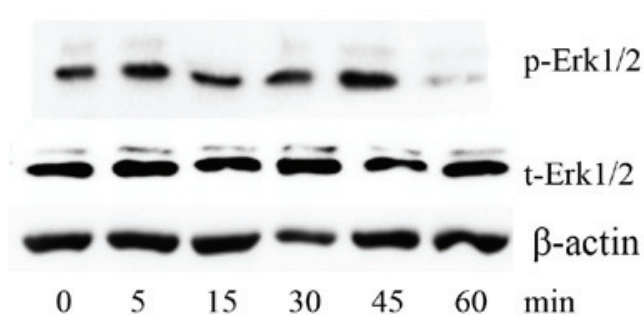

B

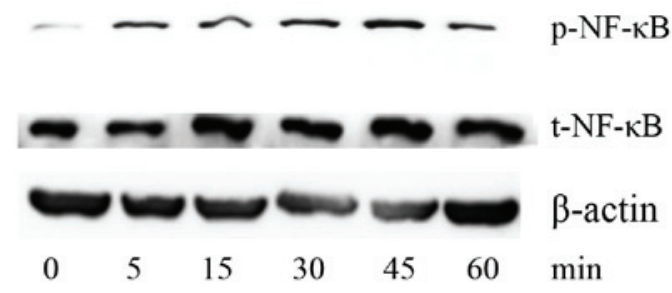

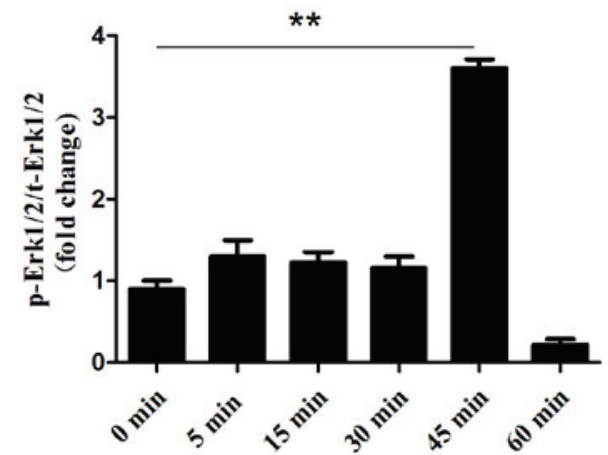

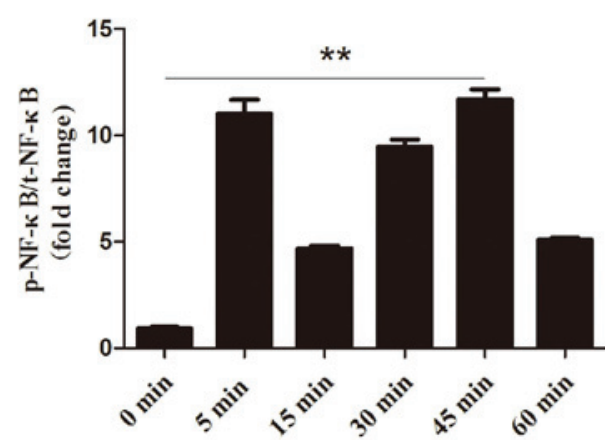

Figure 2. PTH induces the phosphorylation of Erk1/2 and NF-kB during the osteoblastic differentiation of HUVECs. HUVECs were exposed to $10^{-10} \mathrm{mmol} / 1$ PTH for a period of 5-60 min. (A) Representative immunoblots and densitometry data demonstrated that treatment with PTH increased the levels of p-Erk1/2 following 45 min compared with 0 min. (B) Phosphorylation of NF- $\mathrm{KB}$ remained high following $45 \mathrm{~min}$ of PTH exposure in HUVECs. $\mathrm{n}=3$. ** P $<0.01$ vs. the untreated control (0 min). PTH, parathyroid hormone; Erk, extracellular signal-regulated protein kinase; NF, nuclear factor; HUVECs, human umbilical vein endothelial cells; $\mathrm{p}$, phosphorylated; t, total.

Erk1/2 and NF- $\kappa B$ signaling mechanisms mediate PTH promotion. The present study demonstrates the proteinexpression levels of BMP2 and BMP4 following exposure to PTH, PDTC and/or U0126 in HUVECs (Fig. 3A). HUVECs were incubated with U0126 $(1 \mu \mathrm{M})$, PDTC $(10 \mu \mathrm{M})$ or U0126 $(1 \mu \mathrm{M})+$ PDTC $(10 \mu \mathrm{M})$ for $2 \mathrm{~h}$ prior to treatment with $10^{-10} \mathrm{mmol} / \mathrm{l} \mathrm{PTH}$ for $72 \mathrm{~h}$. In addition to inhibition of the Erk1/2 and NF- $\mathrm{KB}$ signaling pathways, the PTH-induced overexpression of BMP2 and BMP4 was significantly reduced in endothelial cells following treatment with PDTC and U0126 ( $\mathrm{P}<0.01$; Fig. 3A and B). Furthermore, PTH-induced BMP2, BMP4, ALP and RUNX2 mRNA overexpression was significantly downregulated as a result of the inhibition of Erk $1 / 2$ and NF-kB signaling pathways $(\mathrm{P}<0.01 ;$ Fig. $3 \mathrm{C})$. These findings suggest that $\mathrm{PTH}$ may promote calcification via Erk1/2 and NF- $\mathrm{KB}$ signaling in HUVECs.

\section{Discussion}

The high prevalence of cardiovascular disease co-occurring with CKD has long been associated with VC (1). A previous study has demonstrated that HUVECs cultured in a high concentration of PTH undergo osteogenic transformation and calcification (21). Furthermore, a previous study indicated that primary and secondary hyperparathyroidism may induce VC (1). PTH is acknowledged for its potent anabolic effect on bone and, furthermore, teriparatide has been used as a therapeutic treatment for patients with severe osteoporosis (22). However, the role of PTH as a risk factor of calcification is not well understood. Low PTH levels have also been reported to be associated with severe arterial calcification (23). Additionally, PTH is known to be a crucial regulator of the cardiovascular system (24).
The results of the present study indicate that PTH may promote the calcification of HUVECs in vitro. VC is an actively regulated process that is similar to osteogenesis $(25,26)$. BMP2, a member of the transforming growth factor- $\beta$ superfamily, regulates osteoblast differentiation and bone formation (27). Overexpression of BMP2 and RUNX2 has been indicated in the calcified vascular smooth muscle cells, which suggests that BMP2 actively regulates the process of VC (6). RUNX2, a key transcription factor belonging to the runt domain gene family, was demonstrated to be overexpressed in the vascular smooth muscle cells (28). These findings suggest that RUNX2 is essential for osteoblast differentiation and may regulate mineralization. Previous results have suggested that HUVECs have acquired phenotypic transitions that are associated with the expression of RUNX2 (21). In the present study, PTH has been demonstrated to promote the calcification of HUVECs by increasing the expression of BMP2, BMP4, RUNX2 and ALP. In a previous study, high levels of PTH induced endothelial to chondrogenic transition in HUVECs (21). Furthermore, these results suggest that PTH may induce the osteoblastic differentiation of HUVECs by mediating the Erk $1 / 2$ and NF- $\mathrm{KB}$ signaling pathways.

PTH is an 84-amino acid peptide with only a few interspecies differences, primarily in the amino terminal portion $(9,29)$. The PTH receptor is a typical G protein-coupled receptor with seven transmembrane domains (9). PTH activates either adenylate cyclase to activate protein kinase A or the phospholipase $\mathrm{C}$ protein kinase $\mathrm{C}$ signaling pathway (30). PTH overloading contributes to left ventricular hypertrophy, myocardial fibrosis and VC, regardless of arterial pressure $(31,32)$. Furthermore, PTH stimulates the renin-angiotensin-aldosterone system, 
A

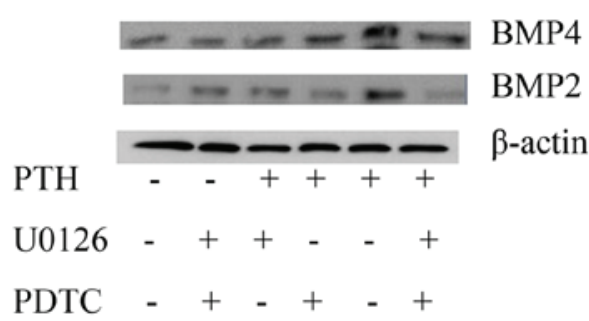

$\mathrm{B}$
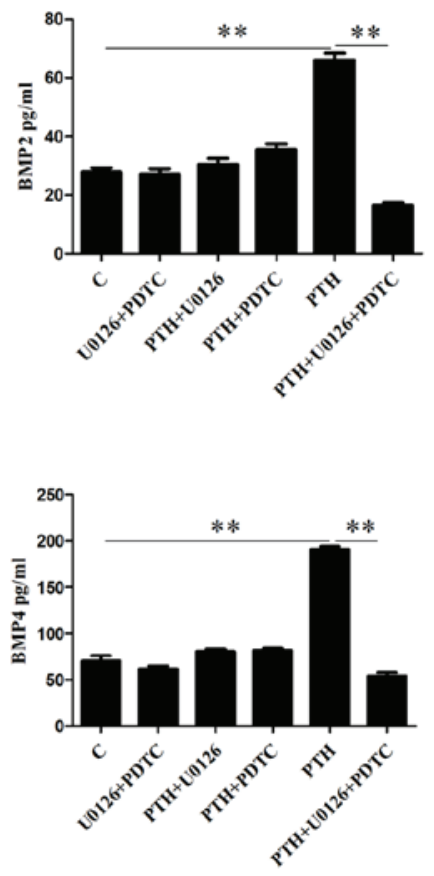
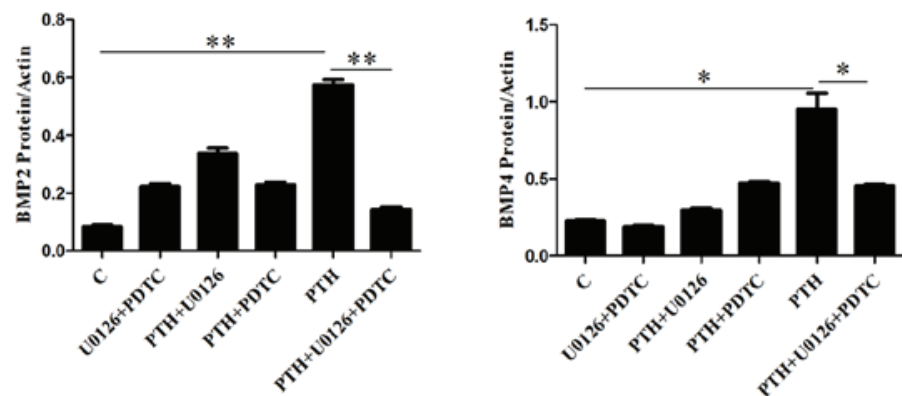

C
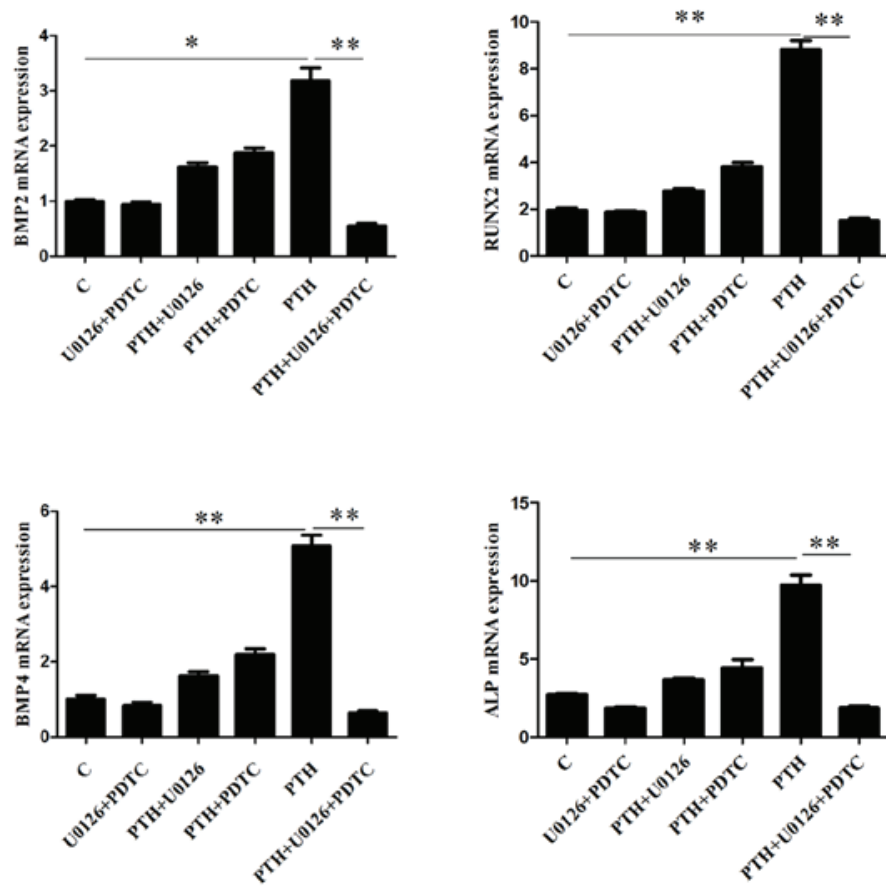

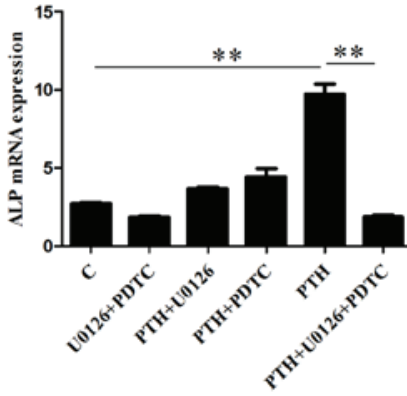

Figure 3. Erk1/2 and NF- $\mathrm{BB}$ are required for the upregulation of BMP2 and BMP4. Endothelial cells were incubated with Erk1/2 inhibitor (U0126, $1 \mu \mathrm{M})$ or $\mathrm{NF}-\kappa \mathrm{B}$ inhibitor (PDTC, $10 \mu \mathrm{M}$ ) or both for $2 \mathrm{~h}$ prior to $72 \mathrm{~h}$ PTH stimulation. (A) Representative immunoblots and densitometry data indicated that inhibition of either Erk1/2 or NF- $\mathrm{B}$ or both abrogated the effect of PTH on BMP2 and BMP4 expression. (B) BMP2 and BMP4 protein expression levels were determined using ELISA in endothelial cells following the different treatments. (C) Reverse transcription-quantitative polymerase chain reaction analysis was performed to assess BMP2, BMP4, ALP, and RUNX2 mRNA expression levels following the different treatments. $\mathrm{n}=3$. ${ }^{*} \mathrm{P}<0.05$ and ${ }^{* * *} \mathrm{P}<0.01$. Erk, extracellular signal-regulated protein kinase; NF, nuclear factor; BMP, bone morphogenetic protein; PTH, parathyroid hormone; RUNX, runt-related transcription; ALP, alkaline phosphatase; PDTC, pyrrolidine dithiocarbamate; C, control cells with no PTH treatment.

sympathetic activity and the secretion of cortisol, which may result in sodium and water retention and ultimately hypertension (33). These changes may further induce endothelial dysfunction and promote VC (34). PTH is a crucial regulator of calcium balance in physiological and pathological conditions associated with cardiovascular events, with a major physiological role in bone homeostasis $(35,36)$. Clinically, patients with CKD suffer from high cardiovascular mortality and adverse cardiovascular events, including coronary microvascular dysfunction, subclinical aortic valve calcification, increased aortic stiffness, endothelial dysfunction and hypertension $(37,38)$. Furthermore, PTH reduces VC mediated by the BMP2-Msh Homeobox 2-Wnt signaling pathway (39-41).

In the present study, HUVECs were cultured with different concentrations of PTH. HUVECs were incubated with $10^{-8}$ to $10^{-11} \mathrm{mmol} / 1 \mathrm{PTH}$ and the results suggested that $10^{-10} \mathrm{mmol} / 1$ significantly increased BMP2 and BMP4, expression compared with the control, with the greatest effect observed at $10^{-10} \mathrm{mmol} / \mathrm{l} \mathrm{PTH}$. In order to gain further insight into the mechanism by which PTH promotes VC, signaling events were examined. Erk1/2 and $\mathrm{NF}-\kappa \mathrm{B}$ have been acknowledged for their essential roles in cell differentiation (42). A previous study has indicated that Erk $1 / 2$ and $N F-\kappa B$ are associated with osteoblastic differentiation and mineralization of HUVECs (20). The results of the present study demonstrate that PTH activates the Erk1/2 and $\mathrm{NF}-\kappa \mathrm{B}$ signaling pathways in HUVECs. Treating HUVECs with Erk $1 / 2$ and NF- $\kappa \mathrm{B}$ inhibitors prevented the PTH-induced overexpression of BMP2, BMP4, ALP and RUNX2. Treatment with the Erk1/2 and NF- $\kappa$ B inhibitors U0126 and PDTC reduced the activation of Erk1/2 and $\mathrm{NF}_{-} \kappa \mathrm{B}$ in HUVECs, which suggests that the PTH-induced promotion of BMP2 expression may be mediated by the Erk1/2 and NF- $\kappa \mathrm{B}$ signaling pathways.

The physiological concentration of PTH is much lower than those applied in the present study; as such, the concentration investigated was not of the usual physiological range. It is important to mention that the majority of previous studies have been performed with the N-terminal fragment of PTH, 
teriparatide, whereas clinical studies use intact PTH (43). As such, mechanistic studies may not reflect clinical conditions. Furthermore, recent studies have indicated that modifications to PTH alter its biological function (43). The carboxyl terminal PTH fragment, which represents $70-95 \%$ of circulating PTH, has a specific effect on calcium homeostasis and bone metabolism, which suggests that carboxyl terminal PTH may increase serum calcium and decrease blood phosphorus (43). In addition, circulating PTH partially oxidizes and loses its PTH receptor-stimulating properties, while remaining detectable by immunoassays (44). Therefore, currently available PTH assay systems may not adequately assess PTH-associated cardiovascular diseases in patients.

In conclusion, the results of the present study demonstrate that PTH serves a crucial role in promoting the osteoblastic differentiation of HUVECs, with Erk1/2 and NF- $\kappa$ B signaling being associated with this process. Furthermore, these findings suggest that PTH may serve a crucial role in promoting VC.

\section{Acknowledgements}

The present study was supported by the Natural Science Foundation of China (grant no. NSFC81371657).

\section{References}

1. Neves KR, Graciolli FG, dos Reis LM, Graciolli RG, Neves CL, Magalhães AO, Custódio MR, Batista DG, Jorgetti V and Moysés RM: Vascular calcification: Contribution of parathyroid hormone in renal failure. Kidney Int 71: 1262-1270, 2007.

2. Oreffo RO, Kusec V, Romberg S and Triffitt JT: Human bone marrow osteoprogenitors express estrogen receptor-alpha and bone morphogenetic proteins 2 and 4 mRNA during osteoblastic differentiation. J Cell Biochem 75: 382-392, 1999.

3. Zappitelli T, Chen F and Aubin JE: Up-regulation of BMP2/4 signaling increases both osteoblast-specific marker expression and bone marrow adipogenesis in Gja1Jrt/+ stromal cell cultures. Mol Biol Cell 26: 832-842, 2015.

4. Nakano-Kurimoto R, Ikeda K, Uraoka M, Nakagawa Y, Yutaka K, Koide M, Takahashi T, Matoba S, Yamada H, Okigaki M and Matsubara H: Replicative senescence of vascular smooth muscle cells enhances the calcification through initiating the osteoblastic transition. Am J Physiol Heart Circ Physiol 297: H1673-H1684, 2009.

5. Boström KI, Rajamannan NM and Towler DA: The regulation of valvular and vascular sclerosis by osteogenic morphogens. Circ Res 109: 564-577, 2011.

6. Hruska KA, Mathew S and Saab G: Bone morphogenetic proteins in vascular calcification. Circ Res 97: 105-114, 2005.

7. Wanner C, Amann K and Shoji T: The heart and vascular system in dialysis. Lancet 388: 276-284, 2016.

8. Silverman R and Yalow RS: Heterogeneity of parathyroid hormone. Clinical and physiologic implications. J Clin Inves 52 1958-1971, 1973

9. Clemens TL, Cormier S, Eichinger A, Endlich K, Fiaschi-Taesch N, Fischer E, Friedman PA, Karaplis AC, Massfelder T, Rossert J, et al: Parathyroid hormone-related protein and its receptors: Nuclear functions and roles in the renal and cardiovascular systems, the placental trophoblasts and the pancreatic islets. Br J Pharmacol 134: 1113-1136, 2001.

10. Isales CM, Sumpio B, Bollag RJ, Zhong Q, Ding KH, Du W, Rodriguez-Commes J, Lopez R, Rosales OR, Gasalla-Herraiz J, et al: Functional parathyroid hormone receptors are present in an umbilical vein endothelial cell line. Am J Physiol Endocrinol Metab 279: E654-E662, 2000.

11. Jiang B, Morimoto S, Yang J, Niinoabu T, Fukuo K and Ogihara T: Expression of parathyroid hormone/parathyroid hormone-related protein receptor in vascular endothelial cells. J Cardiovasc Pharmacol 31 (Suppl 1): S142-S144, 1998.
12. Lishmanov A, Dorairajan S, Pak Y, Chaudhary K and Chockalingam A: Elevated serum parathyroid hormone is a cardiovascular risk factor in moderate chronic kidney disease. Int Urol Nephrol 44: 541-547, 2012.

13. Bro S and Olgaard K: Effects of excess PTH on nonclassical target organs. Am J Kidney Dis 30: 606-620, 1997.

14. Bosworth C, Sachs MC, Duprez D, Hoofnagle AN, Ix JH, Jacobs DR Jr, Peralta CA, Siscovick DS, Kestenbaum B and de Boer IH: Parathyroid hormone and arterial dysfunction in the multi-ethnic study of atherosclerosis. Clin Endocrinol (Oxf) 79: 429-436, 2013.

15. Loncar G, Bozic B, Dimkovic S, Prodanovic N, Radojicic Z, Cvorovic V, Putnikovic B and Popovic V: Association of increased parathyroid hormone with neuroendocrine activation and endothelial dysfunction in elderly men with heart failure. J Endocrinol Invest 34: e78-e85, 2011.

16. Malluche HH, Blomquist G, Monier-Faugere MC, Cantor TL and Davenport DL: High parathyroid hormone level and osteoporosis predict progression of coronary artery calcification in patients on dialysis. J Am Soc Nephrol 26: 2534-2544, 2015.

17. Livak KJ and Schmittgen TD: Analysis of relative gene expression data using real-time quantitative PCR and the 2(-Delta Delta C(T)) method. Methods 25: 402-408, 2001.

18. Zhang M, Sara JD, Wang FL, Liu LP, Su LX, Zhe J, Wu X and Liu JH: Increased plasma BMP-2 levels are associated with atherosclerosis burden and coronary calcification in type 2 diabetic patients. Cardiovasc Diabetol 14: 64, 2015.

19. Yao Y, Bennett BJ, Wang X, Rosenfeld ME, Giachelli C, Lusis AJ and Boström KI: Inhibition of bone morphogenetic proteins protects against atherosclerosis and vascular calcification. Circ Res 107: 485-494, 2010.

20. Zeng Q, Song R, Ao L, Weyant MJ, Lee J, Xu D, Fullerton DA and Meng X: Notch1 promotes the pro-osteogenic response of human aortic valve interstitial cells via modulation of ERK1/2 and nuclear factor- $\kappa \mathrm{B}$ activation. Arterioscler Thromb Vasc Biol 33: 1580-1590, 2013.

21. Wu M, Zhang JD, Tang RN, Crowley SD, Liu H, Lv LL, Ma KL and Liu BC: Elevated PTH induces endothelial-to-chondrogenic transition in aortic endothelial cells. Am J Physiol Renal Physiol 312: F436-F444, 2017.

22. Raggi $\mathrm{P}$ and Kleerekoper M: Contribution of bone and mineral abnormalities to cardiovascular disease in patients with chronic kidney disease. Clin J Am Soc Nephrol 3: 836-843, 2008.

23. Lee SA, Lee MJ, Ryu GW, Jhee JH, Kim HW, Park S, Jung SY, Oh HJ, Park JT, Han SH, et al: Low serum intact parathyroid hormone level is an independent risk factor for overall mortality and major adverse cardiac and cerebrovascular events in incident dialysis patients. Osteoporos Int 27: 2717-2726, 2016.

24. Custódio MR, Koike MK, Neves KR, dos Reis LM, Graciolli FG, Neves CL, Batista DG, Magalhães AO, Hawlitschek P, Oliveira IB, et al: Parathyroid hormone and phosphorus overload in uremia: Impact on cardiovascular system. Nephrol Dial Transplant 27: 1437-1445, 2012.

25. Cannata-Andia JB, Roman-Garcia P and Hruska K: The connections between vascular calcification and bone health. Nephrol Dial Transplant 26: 3429-3436, 2011.

26. Lu R, Wang Q, Han Y, Li J, Yang XJ and Miao D: Parathyroid hormone administration improves bone marrow microenvironment and partially rescues haematopoietic defects in Bmi1-null mice. PLoS One 9: e93864, 2014.

27. Evrard S, Delanaye P, Kamel S, Cristol JP and Cavalier E; SFBC/SN joined working group on vascularcalcifications: Vascular calcification: From pathophysiology to biomarkers. Clin Chim Acta 438: 401-414, 2015.

28. Chen NX and Moe SM: Pathophysiology of vascular calcification. Curr Osteoporos Rep 13: 372-380, 2015.

29. Schluter KD: PTH and PTHrP: Similar structures but different functions. News Physiol Sci 14: 243-249, 1999.

30. Rashid G, Bernheim J, Green J and Benchetrit S: Parathyroid hormone stimulates endothelial expression of atherosclerotic parameters through protein kinase pathways. Am J Physiol Renal Physiol 292: F1215-F1218, 2007.

31. Massimetti C, Achilli P, Zampi G and Feriozzi S: Parathormone and left ventricular hypertrophy. G Ital Nefrol 31: gin/31.6.4, 2014 (In Italian).

32. Liu X, Xie R and Liu S: Rat parathyroid hormone 1-34 signals through the MEK/ERK pathway to induce cardiac hypertrophy. J Int Med Res 36: 942-950, 2008. 
33. Tomaschitz A, Ritz E, Pieske B, Rus-Machan J, Kienreich K, Verheyen N, Gaksch M, Grübler M, Fahrleitner-Pammer A, Mrak P, et al: Aldosterone and parathyroid hormone interactions as mediators of metabolic and cardiovascular disease. Metabolism 63: 20-31, 2014.

34. Rashid G, Bernheim J, Green J and Benchetrit S: Parathyroid hormone stimulates the endothelial expression of vascular endothelial growth factor. Eur J Clin Invest 38: 798-803, 2008.

35. Torres PA and De Broe M: Calcium-sensing receptor, calcimimetics, and cardiovascular calcifications in chronic kidney disease. Kidney Int 82: 19-25, 2012.

36. Thompson B and Towler DA: Arterial calcification and bone physiology: Role of the bone-vascular axis. Nat Rev Endocrinol 8: 529-543, 2012.

37. Paloian NJ and Giachelli CM: A current understanding of vascular calcification in CKD. Am J Physiol Renal Physiol 307: F891-F900, 2014.

38. Johnson RC, Leopold JA and Loscalzo J: Vascular calcification: Pathobiological mechanisms and clinical implications. Circ Res 99: 1044-1059, 2006

39. Cheng SL, Shao JS, Halstead LR, Distelhorst K, Sierra O and Towler DA: Activation of vascular smooth muscle parathyroid hormone receptor inhibits Wnt/beta-catenin signaling and aortic fibrosis in diabetic arteriosclerosis. Circ Res 107: 271-282, 2010.
40. Shao JS, Cheng SL, Charlton-Kachigian N, Loewy AP and Towler DA: Teriparatide (human parathyroid hormone (1-34)) inhibits osteogenic vascular calcification in diabetic low density lipoprotein receptor-deficient mice. J Biol Chem 278: 50195-50202, 2003.

41. Shao JS, Cheng SL, Pingsterhaus JM, Charlton-Kachigian N, Loewy AP and Towler DA: Msx2 promotes cardiovascular calcification by activating paracrine Wnt signals. J Clin Investigation 115: 1210-1220, 2005.

42. Weber JM, Forsythe SR, Christianson CA, Frisch BJ, Gigliotti BJ Jordan CT, Milner LA, Guzman ML and Calvi LM: Parathyroid hormone stimulates expression of the Notch ligand Jagged1 in osteoblastic cells. Bone 39: 485-493, 2006.

43. Goettsch C, Iwata H and Aikawa E: Parathyroid hormone: Critical bridge between bone metabolism and cardiovascular disease. Arterioscler Thromb Vasc Biol 34: 1333-1335, 2014.

44. Hocher B, Armbruster FP, Stoeva S, Reichetzeder C, Grön HJ, Lieker I, Khadzhynov D, Slowinski T and Roth HJ: Measuring parathyroid hormone (PTH) in patients with oxidative stress-do we need a fourth generation parathyroid hormone assay? PLoS One 7: e40242, 2012. 